\title{
Ghrelin Is Effective on Passive Avoidance Memory by Altering the Expression of NMDAR and HTRla Genes in the Hippocampus of Male Wistar Rats
}

\author{
Vahideh Sahraiian ${ }^{1}$ and Homayoun Khazali*1
}

\begin{abstract}
Background: Memory-dependent psychological behaviors have an important role in life. Memory strengthening in adulthood to prevent its defects in aging is a significant issue. The ghrelin endogenous hormone improves memory by targeting glutamatergic and serotonergic circuits. Also, citicoline, a memory strengthening drug in aging, is not recommended to adults due to its side effects. The current study aims to test that ghrelin treatment, like citicoline, would improve passive avoidance memory via expression of the genes encoding the N-methyl-D-aspartate receptor (NMDARl) and the serotonin receptor 1A (HTRla) involved in this process.

Methods: Five groups of adult male rats received (1) saline (as control), (2) $0.5 \mathrm{mg} / \mathrm{kg}$ citicoline, or (3-5) 0.3, 1.5 , and $3 \mathrm{nmol} / \mu \mathrm{l}$ ghrelin). The rats received the drugs via intra-hippocampal injection. Passive avoidance memory was determined using a shuttle box device. The latency to enter the dark chamber before (IL) and after (RL) injection and the total duration of the animal's presence in the light compartment (TLC) were evaluated. Then, the gene expression rates of NMDARI and HTRIa were measured by the Real-Time PCR.

Results: Ghrelin and citicoline had some similar and significant effects on passive avoidance memory, and both increased NMDARI and decreased HTRla expression.

Conclusions: Ghrelin, like citicoline, improves passive avoidance learning by altering the NMDARI and HTRla expression in the hippocampus.
\end{abstract}

Keywords: Citicoline, Ghrelin, HTRla, Intrahippocampal injection, NMDAR1, Passive Avoidance Memory.

\section{Introduction}

Memory-dependent psychological behaviors have an important role in human life. Currently, the increasing prevalence of memory disorders has become a worry $(1,2)$. Thus, researchers are constantly looking for more effective drugs to improve memory than those currently in use. Research has shown that ghrelin plays a role in improving memory. This hormone is produced by the stomach and some other tissues, and once activated, affects target tissues (acyl-ghrelin). The presence of ghrelin receptors, also known as growth hormone secretagogue receptors (GHSRs) and members of the G-protein coupled receptor family, in the hippocampus indicates its role in memory. In the hippocampus, the main ghrelin receptor is GHSR1a. The functional mechanism of ghrelin is not yet fully understood. Because this 28-amino acid peptide targets glutamatergic and serotonergic circuits, ambiguities of its mechanism may be related to these pathways and their gene expression (3-5). Also, citicoline diphosphate-choline (CDPcholine) or citicoline, an intermediate product in phosphatidylcholine production (6) improves passive avoidance memory, cognitive levels, and hippocampal-dependent memory impairment (7, 
8). It is the current drug for the improvement of memory disorders in aging (8), but is not recommended to adults for the prevention of memory disorders, due to possible adverse side effects.

The N-methyl-D-aspartate receptor, a glutamate receptor and ion channel protein in the central nervous system, encoded by the NMDARl is important for controlling synaptic plasticity, memory function, and long-term potentiation (LTP) in the hippocampus $(9,10)$. Also, the serotonin 1a receptor encoded by the HTRIa is an autoreceptor, and coupled with G-protein (Gi), the most widespread of the serotonin (5hydroxytryptamine, 5-HT) receptors in the hippocampus, is related to memory disorders ( 3 , 11, 12).

This study attempts to compare the mechanism of action of ghrelin and citicoline through behavioral tests and the expression of related genes. In this study, citicoline and acyl-ghrelin were injected into the hippocampus, then passive avoidance memory was analyzed by the shuttle box apparatus. Next, NMDARI and HTRla expression was evaluated in the hippocampus.

\section{Materials and Methods Animals}

Sigma-Aldrich Chemicals (St. Louis, MO) company was the source of purchase of Berberine hydrochloride, pilocarpine hydrochloride, scopolamine methylnitrate \& diazepam and all the other chemicals were used.

\section{Animals}

We obtained 30 adults male Wistar rats (aged 8 weeks, 230-250 g) from the Neuroscience Research Center of Shahid Beheshti University. They were kept in a controlled room with a $12 \mathrm{~h}$ light/dark cycle with lights on at 7:00 a.m. and temperature of $22 \pm 2{ }^{\circ} \mathrm{C}$. Food and water were available. All empirical steps including maintenance, stereotaxic surgery, intrahippocampal injection, shuttle box testing, euthanizing, and hippocampal extraction were confirmed by the Regional Ethics Committee of Shahid Beheshti University (IR.SBU.REC.1399.047).

\section{Experimental groups}

The rats were randomly divided into five groups of six rats each. The groups were (1) control, (2) $0.5 \mathrm{mg} / \mathrm{kg}$ citicoline, and (3-5) $0.3,1.5$, or 3 $\mathrm{nmol} / \mu \mathrm{l}$ ghrelin. Drug doses were selected based on previous research $(13,14)$. Ghrelin was purchased from Alfa Aesar Company, Germany, and Citicoline was purchased from Qilu Pharmaceutical Company, China.

\section{Stereotaxic surgery}

The surgical method was based on previous research (15). First, animals were anesthetized with an intraperitoneal injection of a mix of xylazine-ketamine (12 and $60 \mathrm{mg} / \mathrm{kg}$, respectively, both from Kensol Konig, Argentina). The hippocampus was bilaterally cannulated. The animals were situated on a stereotaxic framework (Stoelting Co, Illinois, USA) to implant a 22-gauge stainless steel guide cannula into the CA1 (dorsal hippocampus) with coordinates of " $\mathrm{AP}=-3.8$, $\mathrm{L}= \pm 2.2$ and $\mathrm{DV}=-2.7^{\prime \prime}$ (16). The guide cannula was anchored to the skull by three stainless steel screws and dentistry acrylic cement. It was shorter than the injection cannula $(0.5 \mathrm{~mm})$. After surgery, animals were returned to solo cages to make a recovery for one week. One week after surgery, saline, 0.5 $\mathrm{mg} / \mathrm{kg}$ citicoline, or $0.3,1.5$, or $3 \mathrm{nmol}$ ghrelin were bilaterally injected into CA1 in a volume of $1 \mu \mathrm{l}$ using a 27 -gauge stainless steel injector connected to $1 \mu \mathrm{l}$ Hamilton microinjection system by 20 -polyethylene tubing during 1 min at 9-10 a.m. The control group received only saline. Injection materials were dissolved in sterile $0.9 \%$ saline.

\section{Shuttle box apparatus test}

An ST-5500 shuttle box apparatus (Borj Sanat Co. Tehran-Iran) was used to determine the effects of citicoline and ghrelin on passive avoidance memory based on previous studies protocols $(17,18)$. The shuttle box is a standard device for training trials of passive avoidance memory. One week after surgery, rats were allowed to habituate in the test room for at least half an hour, then for the habituation step, each rat was situated in the light chamber of the 
device. Ten s later, the guillotine door, between the bright and dark chamber, was opened and the rat was allowed to enter the dark chamber. Then the guillotine door was closed, and $30 \mathrm{~s}$ later, the animal was returned into its cage. After $30 \mathrm{~min}$, the training step was started; the rats were trained as in the habituation step except that as soon as the door was closed, a shock was delivered to the floor $(50 \mathrm{~Hz}, 3 \mathrm{~s}$, and $1 \mathrm{~mA}$ intensity). The initial latency (IL) time to enter the dark chamber was recorded. Animals with ILs> 100 s were excluded from the study. The animal was removed from the device and after two minutes, was retrained. This was repeated several times for at least $120 \mathrm{~s}$; the animal did not enter the dark chamber and remained in the bright room. After this step, the animal received the drug as described. Post-training injection aimed to measure the effects of the drug on the memory formation process. The final test step was performed $24 \mathrm{~h}$ after the training. Throughout this step, the animal was put in the light chamber and after $10 \mathrm{~s}$ the guillotine door was opened. After entering all four legs into the dark chamber, the retention latency (RL) was recorded for each rat. Also, the time the animal stayed in the light compartment (TLC) was calculated at $300 \mathrm{~s}$. During the testing step, no electric shock was given.

\section{Real-Time PCR}

After the last test, the animals were euthanized under stress-free conditions by beheading. The brain was removed and the hippocampus collected $(19,20)$. The hippocampus was frozen in liquid nitrogen and stored at $-80{ }^{\circ} \mathrm{C}$ until the real-time measurement. RNA was extracted using Trizol reagent according to the manufacturer's instruction (GeneAll Biotechnology, Korea). The purity and quantity of the RNA were determined using Nanodrop (Thermo Scientific, Germany). High-quality RNAs (A260/280 $\geq 1.8-2.2$ ) were chosen and kept at $-80{ }^{\circ} \mathrm{C}$ to be used for cDNA synthesis later. Then RNA was transcribed into cDNA using a reverse transcription kit (Takara, Bio, Inc). To determine the cDNA's integrity, PCR was performed using glyceraldehydes-3phosphate dehydrogenase (GAPDH) as the housekeeping gene for normalizing data. The gene sequences were extracted from the gene bank to design of primers using the "Primer3" site. Primer sequences selected for this study are listed in Table 1. The reaction was performed at $95^{\circ} \mathrm{C}$ for $15 \mathrm{~min}$, followed by 40 cycles of $95^{\circ} \mathrm{C}$ for $30 \mathrm{~s}, 60^{\circ} \mathrm{C}$ for $30 \mathrm{~s}$, and then $72^{\circ} \mathrm{C}$ for $30 \mathrm{~s}$. Melting curves were analyzed according to the dissociation stage data and reactions were selected with a single peak at melting temperature for further analysis. Eventually, data was normalized with GAPDH, and the $2^{-\Delta \Delta \mathrm{Ct}}$ technique was used to compare the changes in gene expression between the experimental and control groups (fold change) $(21,22)$.

Table 1. Primers used for this study.

\begin{tabular}{llll}
\hline Gene & Primer sequence (5'-3') & NCBI accession number & Product size (bp) \\
\hline \multirow{2}{*}{ NMDARI } & $\begin{array}{l}\text { F: GGAGGAAGATGCACTGACCC } \\
\text { R: GTCATTGATGCCCGTGATGC }\end{array}$ & XM_006233556.3 & 296 \\
\hline \multirow{2}{*}{$\boldsymbol{H T R \boldsymbol { I } \boldsymbol { a }}$} & $\begin{array}{l}\text { F: CTCTCATTTCTGCGCGGTG } \\
\text { R: TGCAGCACAGTACATCCAGG }\end{array}$ & NM_012585.1 & 228 \\
\hline \multirow{2}{*}{$\boldsymbol{G A P D H}$} & $\begin{array}{l}\text { F: CGGCCTTCCTCATTCTTAGCTT } \\
\text { R: ACGGAAACCCTGCCATCCAT }\end{array}$ & NM_017008 & \multirow{2}{*}{103} \\
\hline
\end{tabular}

NMDAR1: N-methyl-D-aspartate receptor subunit 1; HTRla: 5-Hydroxytryptamine receptor 1A;

GAPDH: Glyceraldehyde 3-phosphate dehydrogenase; F: Forward; R: Reverse.

\section{Statistical analysis}

First, data normality was assessed by the Shapiro-Wilk test. The shuttle box test data were presented as medians (min, max). To assess differences between the groups, ANOVA and
Tukey's test was used, and statistics were analyzed using GraphPad Prism, version 9 software. $\mathrm{P}$ values $<0.05$ were considered to be statistically significant. 
For real-time data analysis, gene $\mathrm{Ct}$ values were normalized with the reference gene, and then the $\Delta \Delta \mathrm{Ct}$ method was used to compare gene expression between the groups. Also, the Tukey test was used to compare groups two by two. The ANOVA test was used to determine whether gene expression differences between groups were statistically significant. These calculations were performed by Genex 6 software, statistical analysis by GraphPad Prism, version 9 software. $P$ values $<0.05$ considered to be statistically significant.

\section{Results \\ Effect of ghrelin on shuttle box test}

The duration delay time of the entering the dark chamber, before (IL) and after (RL) injection, as well as, the total duration of the presence in the light compartment (TLC) were evaluated and compared following the Shuttle Box Test (Fig. 1). No significant differences in terms of IL parameters were seen between the groups (Fig. 1A). RL and TLC were significantly greater in all treated groups than in controls (Figs. 1B and $1 \mathrm{C}$, respectively).
A

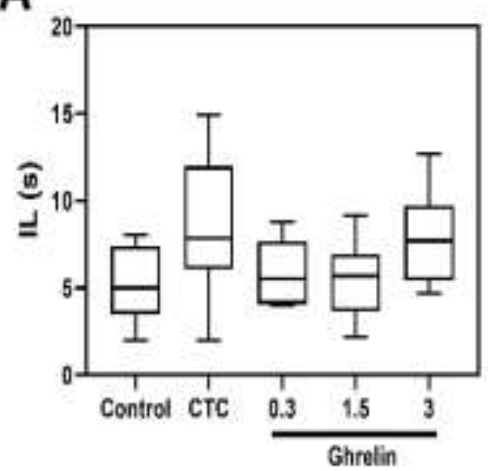

B

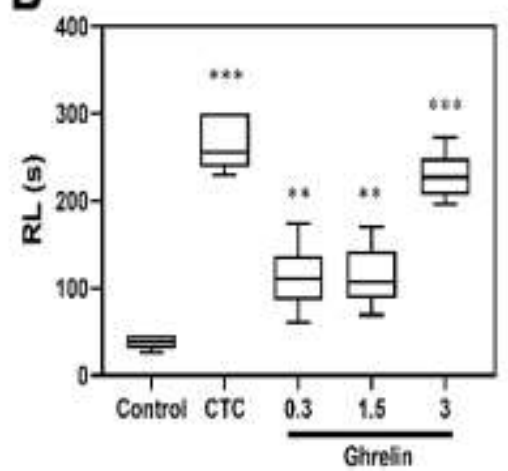

C

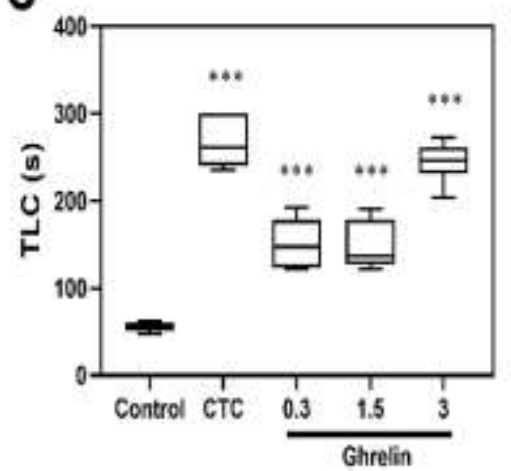

Fig. 1. Shuttle box test results. Shows the latency time (in seconds, s) to enter the dark chamber before foot shock (IL, A), retention phase (RL, B), and time in the light compartment (TLC, C). For IL (A), no significant differences were seen between the control and experimental groups. RL (B) and TLC (C) were both significantly greater than control for both the citicoline- and 0.3, 1.5 , and $3 \mathrm{nmol}$ ghrelin-treated groups $\left(* * \mathrm{p}<0.01,{ }^{* * *} \mathrm{p}<0.001\right.$, vs. control group). Data are shown as median (min, max) of six animals per group. Abbreviation: CTC, citicoline; IL, initial latency; RL, retention latency; TLC, time in the light compartment.

\section{Effect of ghrelin on NMDAR1 gene expression}

NMDARl expression was significantly greater in the right hippocampus than in controls following treatment with CTC or $3 \mathrm{nmol}$ ghrelin, and in the left hippocampus following

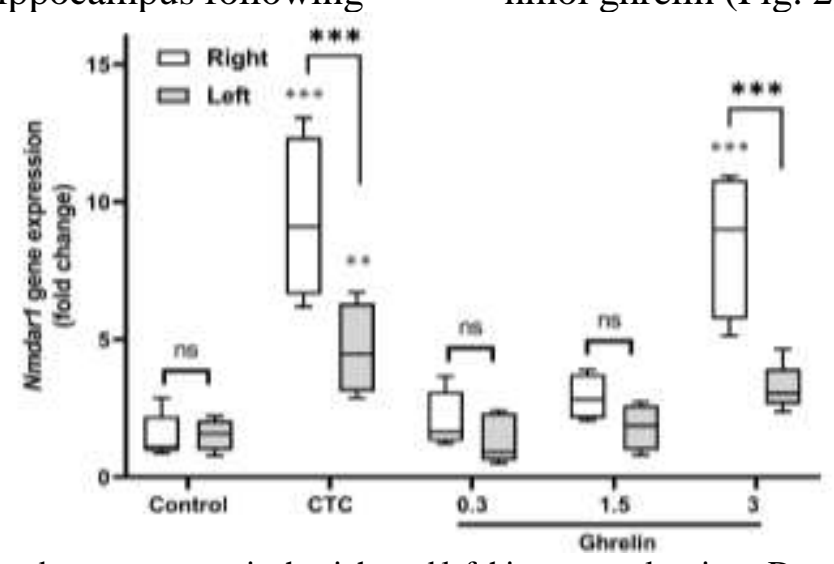

Fig. 2. NMDARl gene expression between groups in the right and left hippocampal regions. Data are shown as median (min, max) of six animals per group. NMDARI expression was significantly greater in the right hippocampus than in controls following treatment with CTC or $3 \mathrm{nmol}$ ghrelin, and in the left hippocampus following treatment with CTC only (**p< 0.01 , ***p< 0.001 , vs. control group). Comparison between the right and left hippocampus in each group shows the significant difference at $\mathrm{p}<0.001$ between CTC and $3 \mathrm{nmol}$ ghrelin. Abbreviation: CTC, citicoline; NMDARl, N-methyl-D-aspartate receptor subunit 1; ns, not significant. 
Effect of ghrelin on HTRla gene expression HTRla expression was significantly less in both the right and left hippocampus than in controls following treatment with CTC or $3 \mathrm{nmol}$ ghrelin. HTRla expression did not differ significantly between the right and left hippocampus for the controls or any of the treatment groups (Fig. 3).

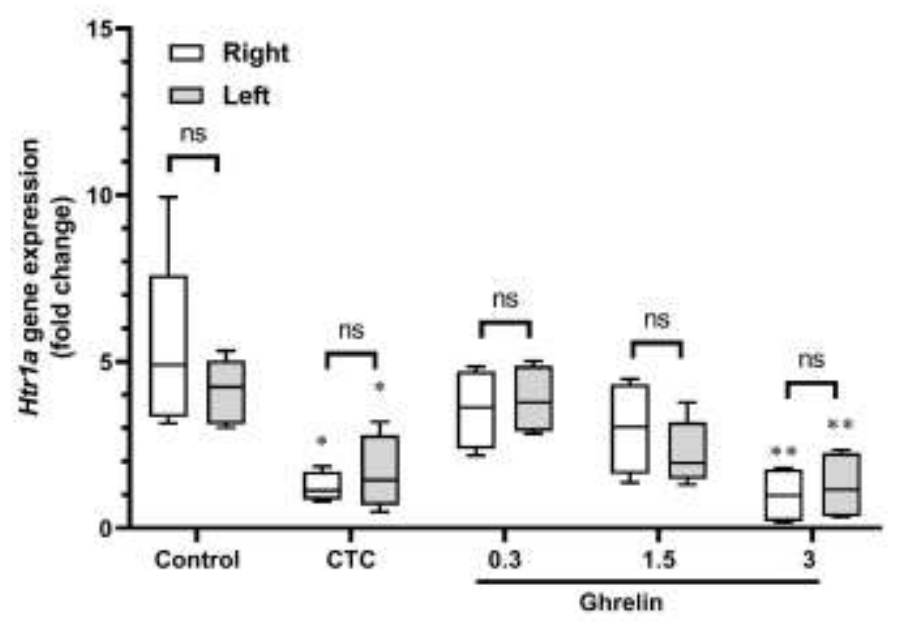

Fig. 3. HTRla gene expression between groups in the right and left hippocampal regions. Data are shown as median (min, max) of six animals per group. HTRla expression was significantly greater in the right hippocampus than in controls following treatment with CTC or $3 \mathrm{nmol}$ ghrelin, and in the left hippocampus following treatment with CTC or 3 nmol ghrelin $\left(*^{*} \mathrm{p}<0.05\right.$, **p< 0.01 , vs. control group). The comparing of changes in HTRla gene expression between the right and left hippocampus in each group shows no significant difference. Abbreviation: CTC, citicoline; HTRla, 5-Hydroxytryptamine receptor 1A; ns, not significant.

\section{Discussion}

Our results showed that citicoline and $3 \mathrm{nmol}$ ghrelin increased both RL and TLC mean times $24 \mathrm{~h}$ after the injection, indicating improved passive avoidance memory. This finding agrees with the work of Carlini et al. $(13,15)$, which showed that ghrelin improves passive avoidance memory. Also, they stated that longterm memory can be improved by ghrelin. These studies confirm and justify our results, but until now, the effects of ghrelin and CTC had not been compared simultaneously. Although the rate of passive avoidance memory improvement in the ghrelin-treated group (3 nmol) was significantly greater than that of the controls, it was less than that of the citicolinetreated group. This discrepancy is probably due to the differences in their mechanisms of action. Ghrelin is a peptide that affects target cells via its receptors (3), but citicoline is a known cellular substance that easily and quickly enter the cell (6). Despite this difference, the effect of ghrelin is similar to that of citicoline.
We also showed that NMDARl expression increased significantly after ghrelin injection (3 nmol), similar to citicoline. Studies have shown that ghrelin, via GHSR1a, stimulates NMDA receptor-mediated synaptic transmission by phosphorylation of this receptor in the hippocampus $(23,24)$. In this regard, Secades reported that citicoline significantly increases ATP brain levels, which positively effect secretion and increase glutamate in the synaptic space (25). This event, in turn, increases NMDA receptor expression, which improves memory via increased synaptic plasticity (26). These studies confirm our results, although, until now, the effects of these two drugs had not been compared simultaneously.

Both citicoline and three nmol ghrelin inhibited HTRla expression. According to studies in rodents, stimulation of 5-HT1A receptors generally produces memory impairments. In contrast, HTRla antagonists facilitate certain types of memory (27). Strong 
evidence indicates that memory impairment is related to both post-synaptic HTRla stimulation and high doses of HTRla (28). Hansson et al. (2011) reported that ghrelin inhibits the serotonergic system. These findings confirm our results. Until now, the effect of citicoline on HTRla had not been studied.

In addition, we found that NMDARl and HTRla expression differed significantly between the right and left hippocampus in homogeneous groups. Consistent with our results, even without treatment, the right and left areas differ functionally $(29,30)$, however, this difference was significantly exacerbated by citicoline and ghrelin.

Summarizing the results of the present and previous studies, ghrelin significantly improved passive avoidance memory while increasing NMDARl and decreasing HTRla expression.

\section{References}

1. Bayliss JA, Lemus MB, Stark R, Santos VV, Thompson A, Rees DJ, et al. Ghrelin-AMPK Signaling Mediates the Neuroprotective Effects of Calorie Restriction in Parkinson's Disease. J Neurosci. 2016;36(10):3049-63.

2. Lu YQ, Luo Y, He ZF, Chen J, Yan BL, Wang $\mathrm{Y}$, et al. Hydroxysafflor yellow A ameliorates homocysteine-induced Alzheimer-like pathologic dysfunction and memory/synaptic disorder. Rejuvenation Res. 2013;16(6):446-52.

3. Hansson C, Haage D, Taube M, Egecioglu E, Salomé N, Dickson SL. Central administration of ghrelin alters emotional responses in rats: behavioural, electrophysiological and molecular evidence. Neuroscience. 2011;180:201-11.

4. Morin V, Hozer F, Costemale-Lacoste JF. The effects of ghrelin on sleep, appetite, and memory, and its possible role in depression: A review of the literature. Encephale. 2018;44(3):256-263.

5. Mahmoudi F, Mohsennezhad F, Khazali H, Ehtesham H. The effect of central injection of ghrelin and bombesin on mean plasma thyroid hormones concentration. Iran J Pharm Res. 2011;10(3):627-32.

6. Matyja E, Taraszewska A, Nagańska E, Grieb P, Rafałowska J. CDP-choline protects motor neurons against apoptotic changes in a model of
Also, we found that citicoline and ghrelin had similar and significant effects on the hippocampus. Ghrelin has fewer side effects than citicoline, but it appears that after further studies, ghrelin may be used in some cases, including drug interactions, side effects, and allergies, to improve passive avoidance memory. Additional medical and behavioral studies are needed to confirm our results.

\section{Acknowledgements}

The authors thank the collaboration of the Regional Department of Animal Sciences and Biotechnology, Faculty of Life Sciences and Biotechnology, for supporting the project. This project was supported by the Shahid Beheshti University (Grant No. D/130/1/3172). The authors declare that they have no conflict of interest.

chronic glutamate excitotoxicity in vitro. Folia Neuropathol. 2008;46(2):139-48.

7. Petkov VD, Mosharrof AH, Kehayov R, Petkov VV, Konstantinova E, Getova D. Effect of CDP-choline on learning and memory processes in rodents. Methods Find Exp Clin Pharmacol. 1992;14(8):593-605.

8. Teather LA, Wurtman RJ. Dietary CDPcholine supplementation prevents memory impairment caused by impoverished environmental conditions in rats. Learn Mem. 2005;12(1):39-43.

9. Li F, Tsien JZ. Memory and the NMDA receptors. N Engl J Med. 2009;361(3):302-303.

10. Ogundele OM, Nanakumo ET, Ishola AO, Obende OM, Enye LA, Balogun WG, et al.

-NMDA R/+VDR pharmacological phenotype as a novel therapeutic target in relieving motorcognitive impairments in Parkinsonism. Drug Chem Toxicol. 2015;38(4):415-27.

11. Albert PR, Fiori LM. Transcriptional dysregulation in anxiety and major depression: 5HT1A gene promoter architecture as a therapeutic opportunity. Curr Pharm Des. 2014;20(23):3738-50.

12. Akbari-Fakhrabadi M, Najafi M, Mortazavian S, Memari A-H, Shidfar F, Shahbazi A, et al. 
Saffron (Crocus Sativus L.), Combined with Endurance Exercise, Synergistically Enhances BDNF, Serotonin, and NT-3 in Wistar Rats. Rep Biochem Mol Biol. 2021;9(4):426-434.

13. Carlini VP, Monzón ME, Varas MM, Cragnolini AB, Schiöth HB, Scimonelli TN, et al. Ghrelin increases anxiety-like behavior and memory retention in rats. Biochem Biophys Res Commun. 2002;299(5):739-43.

14. Xu F, Hongbin H, Yan J, Chen H, He Q, Xu $\mathrm{W}$, et al. Greatly improved neuroprotective efficiency of citicoline by stereotactic delivery in treatment of ischemic injury. Drug Deliv. 2011;18(7):461-7.

15. Carlini VP, Varas MM, Cragnolini AB, Schiöth HB, Scimonelli TN, de Barioglio SR. Differential role of the hippocampus, amygdala, and dorsal raphe nucleus in regulating feeding, memory, and anxiety-like behavioral responses to ghrelin. Biochem Biophys Res Commun. 2004;313(3):635-41.

16. Paxinos $G$, Watson $C$. The rat brain in stereotaxic coordinates. 2013.

17. Babri S, Badie HG, Khamenei S, Seyedlar MO. Intrahippocampal insulin improves memory in a passive-avoidance task in male wistar rats. Brain Cogn. 2007;64(1):86-91.

18. Bavarsad K, Hadjzadeh MA, Hosseini M, Pakdel R, Beheshti F, Bafadam S, et al. Effects of levothyroxine on learning and memory deficits in a rat model of Alzheimer's disease: the role of BDNF and oxidative stress. Drug Chem Toxicol. 2020;43(1):57-63.

19. Lohman RJ, Liu L, Morris M, O'Brien TJ. Validation of a method for localised microinjection of drugs into thalamic subregions in rats for epilepsy pharmacological studies. J Neurosci Methods. 2005;146(2):191-7.

20. Rezayof A, Habibi P, Zarrindast MR. Involvement of dopaminergic and glutamatergic systems of the basolateral amygdala in amnesia induced by the stimulation of dorsal hippocampal cannabinoid receptors. Neuroscience. 2011;175:118-26.
21. Bustin SA. Absolute quantification of mRNA using real-time reverse transcription polymerase chain reaction assays. J Mol Endocrinol. 2000;25(2):169-93.

22. Mo Y, Wan R, Zhang Q. Application of reverse transcription-PCR and real-time PCR in nanotoxicity research. Methods Mol Biol. 2012;926:99-112.

23. Muniz BG, Isokawa M. Ghrelin receptor activity amplifies hippocampal N-methyl-daspartate receptor-mediated postsynaptic currents and increases phosphorylation of the GluN1 subunit at Ser896 and Ser897. Eur J Neurosci. 2015;42(12):3045-53.

24. Berrout L, Isokawa M. Ghrelin upregulates the phosphorylation of the GluN2B subunit of the NMDA receptor by activating GHSR1a and Fyn in the rat hippocampus. Brain Res. 2018;1678:20-26. 25. Secades JJ. Citicoline: pharmacological and clinical review, 2010 update. Rev Neurol. 2011;52 Suppl 2:S1-S62.

26. Danysz W, Parsons CG. Alzheimer's disease, $\beta$-amyloid, glutamate, NMDA receptors and memantine--searching for the connections. $\mathrm{Br} \mathrm{J}$ Pharmacol. 2012;167(2):324-52.

27. Ogren SO, Eriksson TM, Elvander-Tottie E, D'Addario C, Ekström JC, Svenningsson P, et al. The role of 5-HT(1A) receptors in learning and memory. Behav Brain Res. 2008;195(1):54-77.

28. Pitsikas N, Tsitsirigou S, Zisopoulou S, Sakellaridis N. The 5-HT1A receptor and recognition memory. Possible modulation of its behavioral effects by the nitrergic system. Behav Brain Res. 2005;159(2):287-93.

29. Persson J, Herlitz A, Engman J, Morell A, Sjölie D, Wikström J, et al. Remembering our origin: gender differences in spatial memory are reflected in gender differences in hippocampal lateralization. Behav Brain Res. 2013;256:219-28. 30. Frings L, Wagner K, Unterrainer J, Spreer J, Halsband U, Schulze-Bonhage A. Gender-related differences in lateralization of hippocampal activation and cognitive strategy. Neuroreport. 2006;17(4):417-21. 